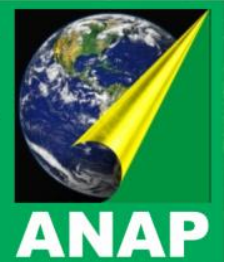

\title{
BIODIVERSIDADE E CONHECIMENTOS TRADICIONAIS: PRESERVAÇÃO OU APROVEITAMENTO?
}

\author{
Adilson Luís Franco Nassaro ${ }^{1}$
}

RESUMO: Biodiversidade e conhecimentos tradicionais são temas apresentados em conjunto quando relacionados à exploração das possibilidades dos recursos naturais, em avançado nível que as pesquisas científicas têm viabilizado, e também às preciosas informações sobre 0 manuseio desses mesmos recursos pelas comunidades tradicionais. Acompanham o dueto candentes questões quanto aos titulares dos benefícios supervenientes. Existem duas frentes no Brasil contemporâneo que defendem, respectivamente, as hipóteses de preservação e de aproveitamento do patrimônio genético no país; essa dualidade reflete um antagonismo em função da burocracia imposta por legislação restritiva à bioprospecção que busca impedir indevidas apropriações em defesa do potencial desenvolvimento do país, ao mesmo tempo em que também inibe o avanço das pesquisas de iniciativa nacional. Enquanto não se resolve o impasse estabelecido, outros fatores de impacto sobre o meio natural provocam extinção de espécies antes do seu idealizado aproveitamento.

Palavras-chave: Biodiversidade, conhecimentos tradicionais, bioprospecção.

\section{INTRODUÇÃO}

Para discorrer sobre o dilema da possível ou justa exploração da chamada biodiversidade, valor em regra associado aos conhecimentos tradicionais, é fundamental a compreensão dos significados da palavra empregada com grande ênfase nos discursos ambiental, econômico e também político. "Biodiversidade" é contração da expressão

\footnotetext{
${ }^{1}$ Mestrando em História, UNESP de Assis (História Ambiental); graduado em Ciências Jurídicas e Sócias; e-mail: adilsonnassaro@hotmail.com.
} 


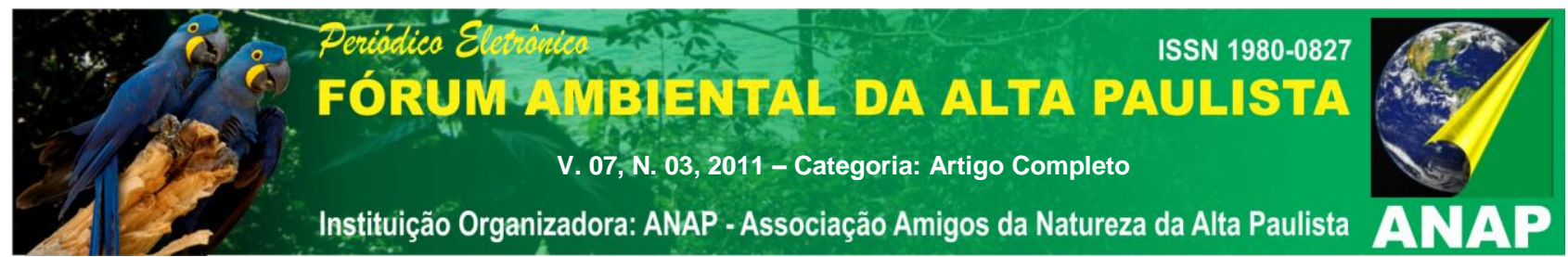

sinônima "diversidade biológica", definida pela Convenção sobre a Diversidade Biológica (CDB), das Nações Unidas, como:

\begin{abstract}
Variabilidade de organismos vivos de todas as origens, compreendendo, dentre outros, os ecossistemas terrestres, marinhos e outros ecossistemas aquáticos e os complexos ecológicos de que fazem parte; compreendendo ainda a diversidade dentro de espécies, entre espécies e de ecossistemas ${ }^{2}$.
\end{abstract}

A CDB foi estabelecida na Conferência Mundial Rio 92, como um construto legal firmado em âmbito internacional por países membros. Constitui uma das três chamadas "Convenções do Rio", resultantes da Conferência das Nações Unidas sobre Meio Ambiente e Desenvolvimento, evento também conhecido como Cúpula da Terra, ou Conferência Mundial "Rio 92", ou simplesmente "ECO-92" As outras duas Convenções são: a de "Desertificação" e a de "Mudanças Climáticas". A CDB significou um ponto de convergência de expectativas que extrapolaram metas de nações, projetando um futuro de continuidade da vida no planeta expresso nas condições propícias à preservação da diversidade biológica ${ }^{3}$.

$\mathrm{Na}$ análise da biodiversidade como um recurso - ou melhor, um conjunto de recursos -, compreende-se que a diversidade genética que a caracteriza significa a máxima manifestação do patrimônio natural, como uma das formas de riqueza, a biológica, como descreve Roberto Naime: "representando milhões de anos de evolução, concentrados no espaço e no tempo, e que podem representar um patrimônio imensurável e intangível de codificações genéticas com suas devidas atribuições"4.

Tal como ocorre na esfera do direito privado no âmbito interno da maioria das nações, a regra do direito internacional consiste no respeito à propriedade dos bens móveis e imóveis e seu potencial aproveitamento levando-se em conta a titularidade desses objetos de interesse. Já as fronteiras reconhecidas entre os países e os

\footnotetext{
2 BRASIL. A Convenção sobre Diversidade Biológica - CDB. Brasília: Ministério do Meio Ambiente, Secretaria de Biodiversidade e Florestas, 2000, artigo $2^{\circ}$.

${ }^{3}$ No Brasil, o Decreto Legislativo oㅜ 2, de 03 de fevereiro de 1994, aprovou o texto da CDB, acolhendo-a no ordenamento jurídico nacional.

${ }^{4}$ NAIME, Roberto. Sistemas, Riqueza e a Biodiversidade. Artigo publicado no portal "Ecodebate" em 29-11-2010. Disponível em <http://www.ecodebate.com.br/2010/11/29/sistemas-riqueza-e-a-biodiversidadeartigo-de-roberto-naime/>. Acesso em: $31 \mathrm{dez} .2010$.
} 


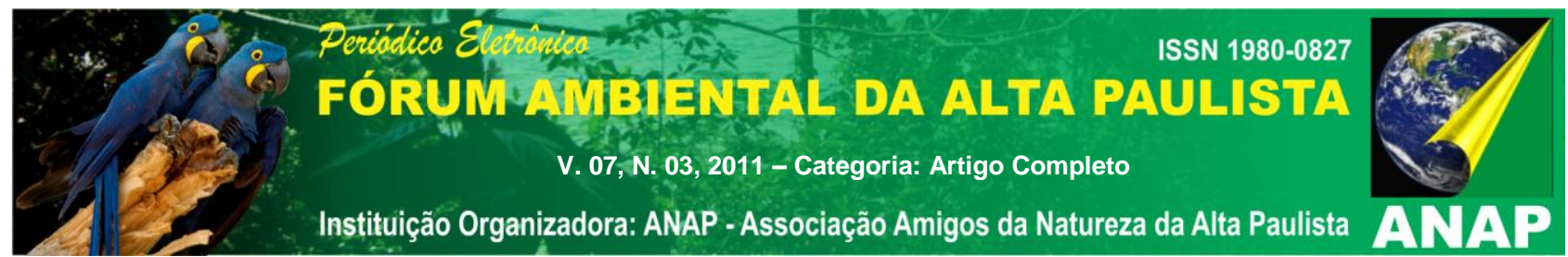

respectivos espaços territoriais, aéreos e marítimos são critérios normalmente observados, ou que deveriam ser observados, para a noção da titularidade, posse e propriedade, na relação dos integrantes da comunidade internacional. $E$ o aperfeiçoamento dos critérios conveniados tem prestigiado o respeito aos direitos de comunidades específicas em face do aproveitamento de conhecimentos tradicionais associados à biodiversidade.

\section{PROTEÇÃO E UTILIZAÇÃO DA BIODIVERSIDADE}

O tema é caro ao Brasil pela grandeza do patrimônio genético característico do seu diversificado e continental território, qualificando-o como o país mais biodiverso do mundo. Portanto, ostenta a condição de titular de ricos "bancos genéticos" constituídos pelos biomas que se encontram dentro de suas fronteiras ou ocupam parte expressiva de sua área geográfica. Essa qualidade que se projeta como um futuro benefício às pessoas que vivem sob a tutela do Estado brasileiro, paulatinamente vem sendo demonstrada mediante registros sobre a fauna do país, entre outros indicadores:

Uma das expressões dessa grande biodiversidade é a sua rica e exuberante fauna, constituída de mais de 100 mil espécies, entre mamíferos, aves, anfíbios, peixes, répteis, insetos e outros invertebrados. Em uma recente análise sobre a biodiversidade, Lewinsohn e Prado (2002) estimaram que entre $10 \%$ e $20 \%$ de toda a diversidade conhecida no planeta (180 a 220 mil espécies) está no Brasil, apesar de apenas 10\% ser conhecida ${ }^{5}$.

No entanto, o tamanho de tal riqueza é inversamente proporcional às pesquisas já desenvolvidas e ao conhecimento de suas reais possibilidades, conforme registrou Giovana Girardi em 2008 ao confirmar que o país inclusive desconhece a maior parte de suas plantas, animais e microrganismos. Justificando suas conclusões, a autora relatou manifestação de Bráulio Dias, então diretor de Conservação da Biodiversidade e que veio

\footnotetext{
${ }^{5}$ BRESSAN, Paulo Magalhães, KIERULFF, Maria Cecília Martins, SUGIEDA, Angélica Midori: coordenação geral. Fauna ameaçada de extinção no estado de São Paulo. São Paulo: Fundação Parque Zoológico de São Paulo, 2009, p. 17.
} 


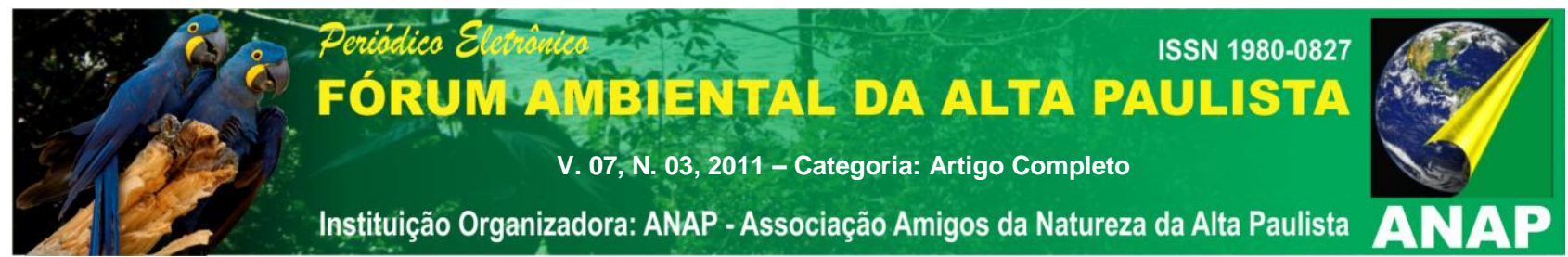

a assumir pouco tempo depois a Secretaria de Biodiversidade e Florestas do mesmo Ministério:

Se mantivermos o ritmo atual de descobertas de novas espécies, levaremos de 800 a 1.000 anos para conhecer tudo", concluindo com uma retificação: "ou melhor, esse é o tempo para descobrir o básico, a taxionomia. Porque para conhecer toda a biodiversidade, a ponto de poder aproveitá-la em benefício da sociedade, estamos ainda mais longe ${ }^{6}$.

Trata-se, portanto, de um potencial aproveitamento econômico de valor incalculável, pois também são incalculáveis os benefícios que o homem pode alcançar em seu bem estar, partindo de pesquisas e do encontro de conhecimentos tradicionais com o conhecimento científico. As possibilidades encontradas nesse espaço propício ao desenvolvimento trouxeram a convicção de que o futuro da humanidade será vinculado à exploração da biodiversidade e, por isso, despertam a atenção e movimentam ações que nem sempre contemplam a preservação da natureza. Em contrapartida, despontam iniciativas que defendem a identidade de grupos titulares - povos, tribos, aldeias, comunidades - ou detentores desses mesmos recursos junto às técnicas tradicionais de seu manejo. Argumenta-se que o uso tradicional sustentado dos recursos por essas comunidades teria sido responsável, em grande medida, pela preservação da diversidade genética hoje reconhecida como valiosa.

Em razão de que não existia um marco regulatório internacional ainda no final do segundo milênio, surgiram entraves no plano do ordenamento jurídico diante da troca de informações - característica da contemporaneidade - e o sistema de registro de patentes com regras diferentes em cada país. Na virada do século, havia uma sensação de que o Brasil não dispunha de qualquer controle sobre acordos com multinacionais, especialmente as farmacêuticas, o que provocou a edição da Medida Provisória 2.186-16, de 2001, como tentativa de prover antídoto à biopirataria, em formato de instrumento extravagante de imposição legislativa do Poder Executivo Federal de caráter emergencial. Mas a provisoriedade, nesse caso, manteve-se apenas na nomenclatura do ato, por falta de aprovação de projeto de lei posterior, ainda em tramitação.

\footnotetext{
${ }^{6}$ GIRARDI, Giovana. Biodiversidade, essa desconhecida. Jornal "O Estado de São Paulo". 07 de agosto de 2008.
} 


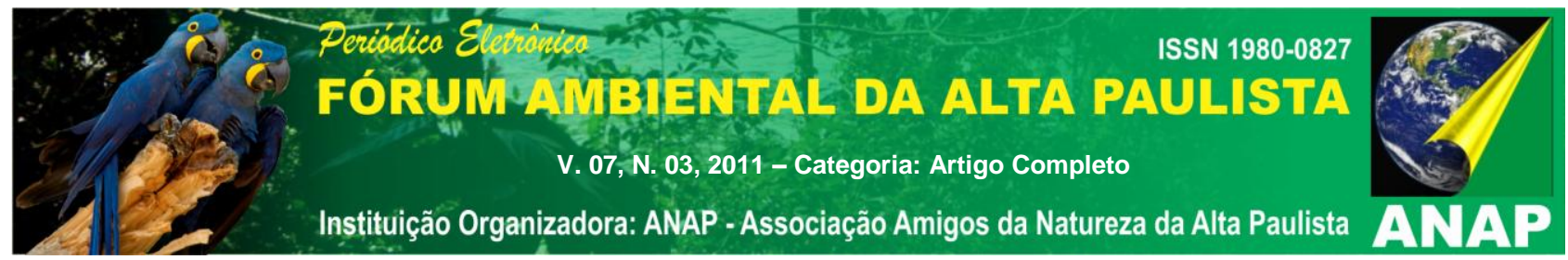

Tal legislação que nasceu na perspectiva de proteção imediata dos recursos naturais e de seus potenciais benefícios passou a receber sérias críticas no meio acadêmico pelo efeito da imposição de restrições, avaliadas como negativas ao progresso científico nacional. Os pesquisadores alegam que enfrentam dificuldades com a burocracia para aprovação de projetos junto ao Ministério do Meio Ambiente, o que consideram desestímulo a pesquisa do patrimônio genético. Na linha de raciocínio dos pesquisadores, paradoxalmente a norma acabaria por incentivar a biopirataria, posto que seria mais fácil um cientista estrangeiro colher no Brasil amostras, já suficientes para estudo, e patentear um composto em país onde não há exigências quanto à determinação de origem para que uma substância ainda não identificada seja registrada. Também os pesquisadores manifestam insegurança no país, temendo que direitos sejam reclamados por comunidades ou povos indígenas quanto ao resultado de seus trabalhos, conforme prevê o referido marco legal brasileiro conhecido como "lei de bioprospecção", em harmonia com a $\mathrm{CDB}^{7}$.

Nesses termos, a posição do governo brasileiro mantém-se cautelosa e a norma "provisória" se perpetua para além de uma década, ainda que algumas decisões normativas tenham simplificado exigências em níveis mais básicos de pesquisa, exemplo daquelas relacionadas à taxonomia. Então, por um lado o governo brasileiro defende a pesquisa do patrimônio genético nacional como caminho para o futuro promissor que se alcançará por meio da bioprospecção - que tem por significado "atividade exploratória que visa identificar componente do patrimônio genético e informação sobre conhecimento tradicional associado, com potencial de uso comercial", nos termos do inciso VII, do artigo 7º, da citada Medida Provisória 2.186-16. Por outro lado, impõe rigorosas regras e condições que caracterizam uma verdadeira "bioburocracia", como a obrigatoriedade de que qualquer atividade de pesquisa nessa área, inclusive cada fase anterior ao acesso à amostra de interesse, deva ser pré-aprovada pelo Conselho de Gestão do Patrimônio Genético (CGen), órgão criado no Ministério do Meio Ambiente pela mesma Medida Provisória (artigo 10), com caráter deliberativo e normativo.

\footnotetext{
7 LEONE, Cínthia. Cientistas criticam lei de bioprospecção. Jornal da UNESP, ano XXII, n. 262, dezembro de 2010, p. 5.
} 


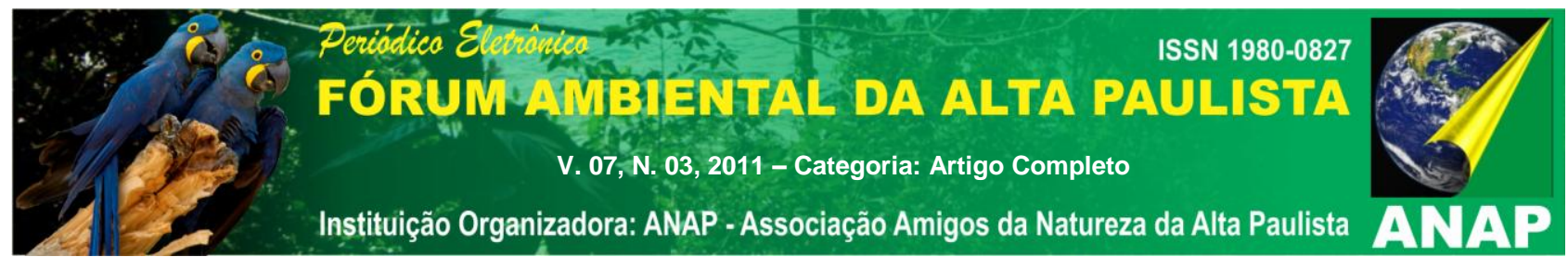

Nesse sentido, a bioburocracia significa uma reação à biopirataria que, pelos seus efeitos generalizantes, torna-se capaz de prejudicar a bioprospecção de interesse nacional, quando seu objetivo seria protegê-la. Diante desse nó que tarda em ser desfeito, a própria Secretaria de Assuntos Estratégicos da Presidência da República reconheceu que:

As excessivas exigências burocráticas aos projetos de pesquisa em biodiversidade e a incapacidade dos órgãos responsáveis de autorizar a tempo as pesquisas têm desestimulado a atividade científica nesse campo e, quase sempre, têm posto na ilegalidade os poucos pesquisadores que se arriscam a trabalhar. O resultado é que, muitas vezes, o cientista tem recebido o mesmo tratamento que o biopirata ${ }^{8}$.

Em razão dessa constatação e acompanhando os defensores de uma nova lei regulamentadora da questão, na mesma manifestação o órgão federal propôs solução contemporizadora que passa pela mudança legislativa, de modo a:

Substituir o marco legal atual por uma lei que diminua drasticamente o custo de transação da pesquisa em biodiversidade. Ao mesmo tempo, deve-se procurar formas mais eficientes de garantir que as comunidades locais que preservam a biodiversidade e que detêm conhecimento tradicional associado ao seu patrimônio genético sejam efetivamente compensadas por esse serviço ${ }^{9}$.

O tema é palpitante e as questões legais indicadas devem ensejar mudanças, levando-se em conta que a legislação atual veda o acesso não autorizado ao patrimônio genético; porém, deixa de dispor como os royalties podem ser pagos e qual é o mecanismo e valores devidos para a repartição de benefícios. Aliado a esse fator, constatam-se avanços científicos na área da biotecnologia a cada ano junto à percepção de um universo ainda a ser descoberto. Fato é que, ao lado do interesse científico, surgiram possibilidades de obtenção de lucros em função de novos produtos derivados de pesquisas patrocinadas por empresas multinacionais com notável impulso na década

\footnotetext{
${ }^{8}$ Secretaria de Assuntos Estratégicos - SAE. Estímulo à pesquisa em biodiversidade. Brasília: Portal SAE, blog archive, 02 dez. 2009. Disponível em: <http://www.sae.gov.br/site/?p=459>. Acesso em: 02 jan. 2011.

${ }^{9}$ Ibide, op. cit.
} 


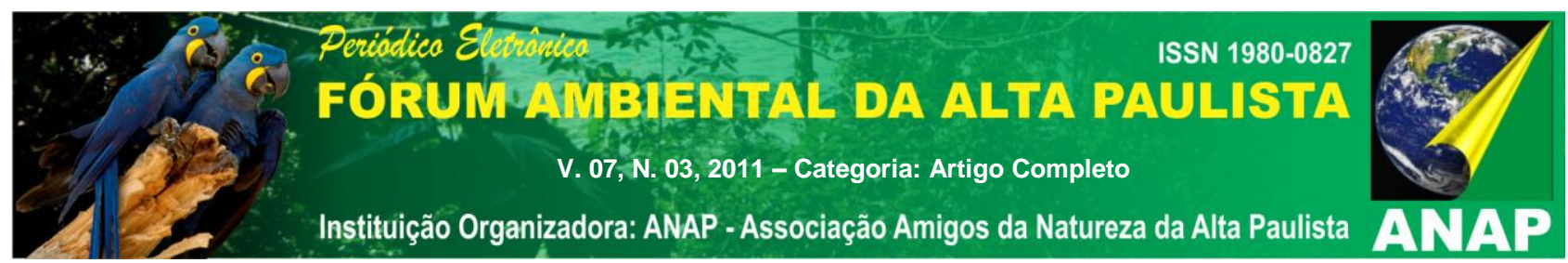

1990, projetando o século XXI como o "século biotecnológico", título cunhado em 1999 por Jerimy Rifkin ${ }^{10}$.

Enquanto a renovação legislativa não ocorre, o Instituto Brasileiro do Meio Ambiente e dos Recursos Naturais Renováveis (Ibama) demonstra aperfeiçoamento nos métodos e recursos de fiscalização, impondo autuações ainda com sanções pendentes de recursos, porém com expressão suficiente para se dimensionar a gravidade dos fatos irregulares constatados em período recente de sua atuação, como observa Nassif em artigo publicado em 2011:

O Ibama notificou cerca de 30 instituições de pesquisa e 70 empresas muitas delas multinacionais que atuam no Brasil - investigadas por suposta coleta ilegal de material genético da biodiversidade, prática conhecida como biopirataria. Algumas companhias já foram autuadas por não entregarem ao Ibama documentação solicitada para verificar se houve acesso ao patrimônio genético sem conhecimento prévio do governo como determina a lei. As investigações se concentram em empresas de grande porte, que atuam nos ramos de cosméticos, medicamentos, alimentos e biotecnologia. Segundo o lbama, as investigações indicam um "volume gigantesco" de elementos da biodiversidade brasileira enviados ilegalmente para o exterior. No uso genético da biodiversidade se incluem: princípios ativos de plantas com uso medicinal por comunidade ribeirinhas ou indígenas, venenos de répteis isolados em laboratório ou componentes do genoma de animais ou micro-organismos. As notificações integram a segunda fase da Operação Novos Rumos, deflagrada em agosto de 2010. Na primeira etapa, o lbama se concentrou em empresas que procuraram o Conselho de Gestão do Patrimônio Genético (CGen) do Ministério do Meio Ambiente depois de realizar suas pesquisas. (...). Agora, entretanto, os alvos são conglomerados industriais que vendem no Brasil e no exterior produtos com a marca da fauna e flora brasileiras, sem sequer procurar o CGen para legalizar suas pesquisas ${ }^{11}$.

As informações colhidas pelo articulista junto ao coordenador de fiscalização do Ibama, Bruno Barbosa, também dão conta de que faz sentido preocupar-se com a biosprospecção sob a cobertura de pesquisa científica do meio acadêmico, com o

\footnotetext{
${ }^{10}$ MOREIRA, Teresa Cristina. Conhecimentos tradicionais associados à biodiversidade no Brasil e a sua abordagem jurídica no limiar do século biotecnológico. In GROSTEIN, Marta Dora, org. Ciência ambiental: questões e abordagens. São Paulo: Annablume; FAPESP, 2008, p. 166.

11 NASSIF, Luis. O cerco à biopirataria. Artigo publicado em 06.05.2011, disponível em <http://www.advivo.com.br/blog/luisnassif/o-cerco-a-biopirataria>. Acesso em: 25 mai. 2011.
} 


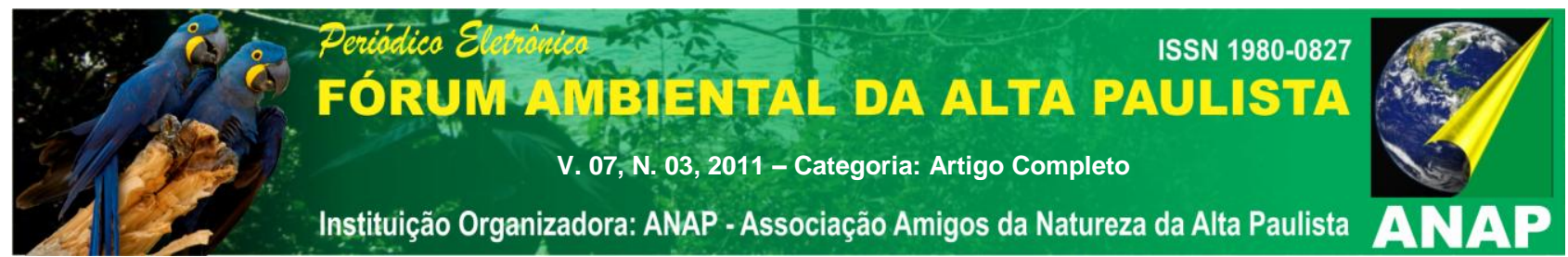

conhecimento desautorizadamente apropriado por grupos empresariais interessados na exploração econômica dos recursos, conduta igualmente caracterizadora da biopirataria. Essa circunstância leva o CGen a adotar uma postura considerada rigorosa quanto ao controle e expedição de autorizações em todos os níveis:

[...] prática usual, segundo o coordenador do lbama, é a apropriação irregular de conhecimento de instituições de pesquisa brasileiras por multinacionais, como ocorre no caso de micro-organismos ou elementos da fauna e da flora usados para o desenvolvimento de novos materiais. $\mathrm{Na}$ prática, os estudiosos usam autorizações para pesquisa acadêmica, que acabam sendo patenteadas no exterior por indústrias de ponta. - Isso acontece o tempo todo. É natural. Várias empresas buscam os institutos para desenvolver seus produtos. Tudo isso, muito distante da legislação, diz o coordenador do lbama ${ }^{12}$.

Nesse cenário não existe certeza se haverá tempo e também oportunidade para o preconizado desenvolvimento com os benefícios garantidos por uma ação fiscalizadora nos termos propostos, e que poderia favorecer o país. Paira ainda sobre toda a humanidade a pesada nuvem da constatação de perda de biodiversidade pela extinção de espécies, tanto animais quanto vegetais, que caracterizou as últimas décadas de rápida expansão industrial, de exponencial crescimento da população humana e de notável intervenção no meio natural. Em 1999, especialista concluíram que ocorre acelerada extinção de espécies em todo o mundo, a cada dia, a cada hora e a cada minuto, com mais de 5.000 espécies ameaçadas e, se não houver reversão da tendência, uma em cada quatro espécies vegetais, por exemplo, poderá estar extinta em torno do ano $2050^{13}$.

\section{MOVIMENTAÇÃO INTERNACIONAL EM DEFESA DA DIVERSIDADE BIOLÓGICA}

Diante do complexo quadro de percepção de perdas e de esperanças, a comunidade internacional, por meio da Assembléia Geral das Nações Unidas, declarou 2010 como o "Ano Internacional da Biodiversidade" exatamente com o objetivo de

\footnotetext{
${ }^{12}$ Ibid.

13 KINGSLEY, Rebecca. Espécies ameaçadas: guia prático. Por Rebecca Kingsley. São Paulo: Nobel, 1999, p. 07.
} 


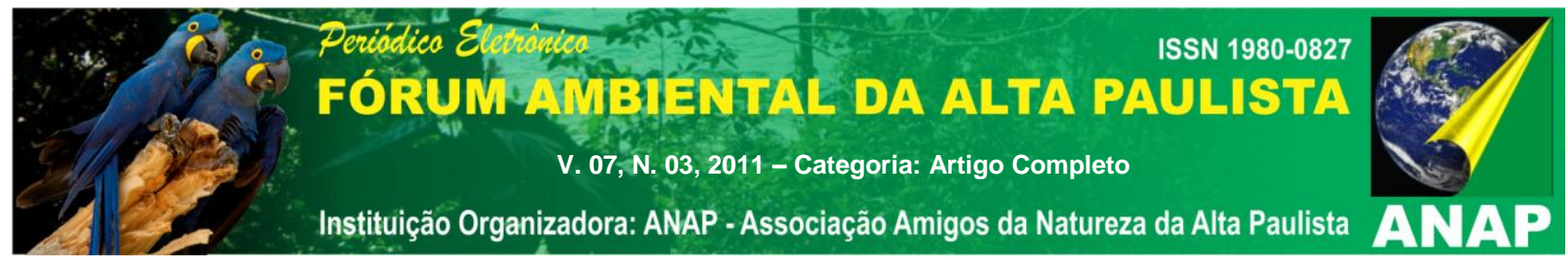

conscientizar os povos sobre a importância da diversidade biológica para o planeta, em uma campanha global para estimular o mundo a agir pela proteção de todo o seu patrimônio genético ${ }^{14}$.

Além disso, o emblemático ano de 2010 foi eleito, ainda em abril de 2002, pelas Partes da CDB (que já somam 192 países e mais a União Européia), como prazo para uma tentativa consensual de "redução significativa da taxa atual de perda de biodiversidade em níveis global, regional e nacional, de forma a contribuir para a redução da pobreza e para benefício de toda a vida na Terra“. Mesmo sem um índice definível, o objetivo foi logo aprovado pela Cúpula Mundial sobre Desenvolvimento Sustentável (a Cúpula "Rio + 10"), em Joanesburgo, no mesmo ano de 2002, e pela Assembléia Geral da ONU e também foi incorporado como uma nova meta em um dos "Objetivos de Desenvolvimento do Milênio", denominado "Assegurar a Sustentabilidade Ambiental"15. Por fim, em outubro de 2010 ocorreu a 10aㅗ Reunião da Conferência das Partes da Convenção (COP 10), em Nagoya, no Japão, para avaliação do período e a elaboração de um novo plano estratégico para as próximas décadas, incluindo uma visão para 2050 e uma meta para a biodiversidade a ser alcançada em 2020.

Apesar dos esforços mobilizados pela comunidade internacional em tempo recente, concluiu-se que o objetivo traçado para 2010 não foi atingido no que refere à redução de taxa de perda de biodiversidade. Constataram-se, por outro lado, múltiplas indicações de contínuo declínio da biodiversidade nos três dos seus principais componentes que são: genes, espécies e ecossistemas. Como pontuou Ahmed Djoghlaf, Secretário Executivo da Convenção, na apresentação do documento de análise "Panorama da Biodiversidade Global 3" de 2010, mesmo com os avanços das medidas positivas adotadas por países, que abrangem o desenvolvimento de nova legislação, o estabelecimento de mecanismos de avaliação de impacto ambiental, a participação em iniciativas de gestão ou de cooperação transfronteiriça e promoção do envolvimento da comunidade na gestão dos recursos biológicos, as Partes confirmaram em grande maioria que "as cinco principais

14 UNESCO. 2010 - Ano Internacional da Biodiversidade. Apresentação disponível em: $<$ http://www.unesco.org/pt/brasilia/about-the-unesco-brasilia-office/prizes-and-celebrations-in-brazil/2010 -international-year-of-biodiversity/>. Acesso em: 31 dez. 2010.

${ }^{15}$ SECRETARIADO DA CONVENÇÃO SOBRE DIVERSIDADE BIOLÓGICA. Panorama da Biodiversidade Global 3. Brasília: Ministério do Meio Ambiente, Secretaria de Biodiversidade e Florestas, 2010. Disponível em <http://www.mma.gov.br/portalbio>. Acesso em: 13 mar. 2011. 


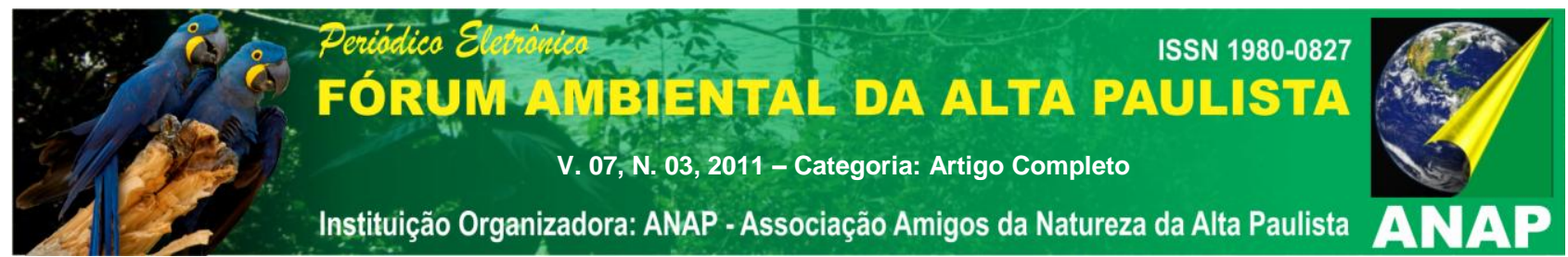

pressões continuam a afetar a biodiversidade dentro de suas fronteiras: a perda de hábitat, o uso não sustentável e a sobrexploração de recursos, as mudanças climáticas, as espécies exóticas invasoras e a poluição ${ }^{16}$.

Além da Convenção da Biodiversidade, as duas outras da tríade "Convenções do Rio": a da "Desertificação" e a de "Mudanças Climáticas" guardam relação com a questão da preservação da diversidade biológica pela análise de coincidentes impactos sobre a vida terrestre, sob a dimensão da perda de hábitat (com a desertificação de áreas) e das alterações climáticas provocadas pela ação do homem no período pós-industrial, ou seja, nos últimos 150 anos aproximadamente, o que impôs acelerado ritmo de mudanças no planeta.

A movimentação mundial tem um mérito inquestionável. Apesar das análises pouco otimistas, demonstrou-se a existência de um bem assentado caminho a ser percorrido pelos membros da comunidade internacional na condição de protagonistas do processo de compatibilização do desenvolvimento e da preservação da vida, tendo por horizonte a diminuição da perda de biodiversidade e como direção a união dos povos em torno desse mesmo objetivo.

\section{CONHECIMENTOS TRADICIONAIS: BENEFÍCIOS E PROTEÇÃO LEGAL}

Desde tempos imemoriais o homem reuniu conhecimentos associados aos recursos da natureza que o rodeava, compondo paulatinamente um repertório de informações úteis ao seu melhor aproveitamento. O que caracteriza um conhecimento como tradicional é o fato de que algumas informações sobre o manuseio e utilização de recursos naturais permanecem no âmbito de comunidades locais e, portanto, ainda não se encontram difundidos pelos mecanismos usuais de registro ou pelos contemporâneos meios de troca de informações. Significam, por isso, um valor inerente à sua própria originalidade, na condição de propriedade imaterial, no caso intelectual.

\footnotetext{
${ }^{16}$ Ibid, p. 07.
} 


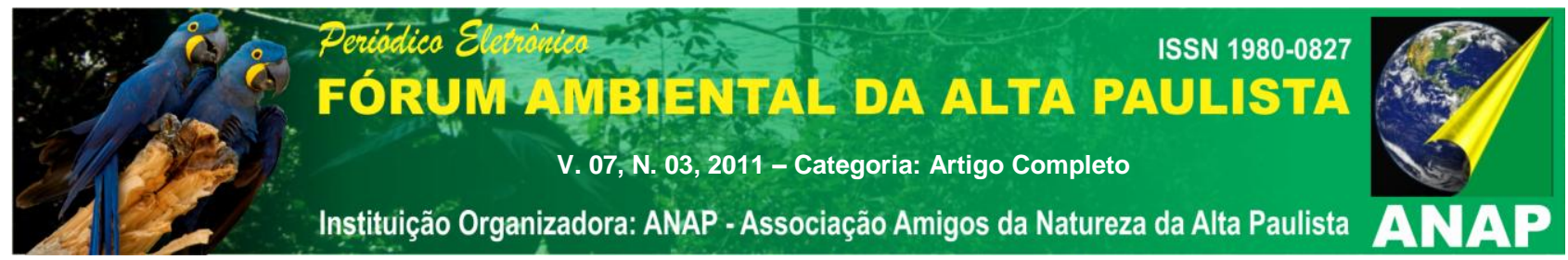

Tratando-se do reconhecimento dos direitos quanto ao aproveitamento desses saberes, aplicam-se obviamente os conceitos jurídicos a eles relacionados. A Medida Provisória ํㅡ 2.186-16/01 regrou o acesso ao patrimônio genético no Brasil, bem como a proteção e o acesso ao conhecimento tradicional associado com repartição de benefícios, trazendo em seu artigo 7$^{\circ}$, inciso II, o significado da expressão - "conhecimento tradicional associado: informação ou prática individual ou coletiva de comunidade indígena ou de comunidade local, com valor real ou potencial, associada ao patrimônio genético".

A junção do conhecimento científico ao conhecimento tradicional significa ao pesquisador economia do tempo necessário para obter soluções que permitam um aproveitamento em escala de determinado recurso natural, pela exploração de amostra representativa do patrimônio genético em estudo. A fórmula simples utilizada, ou a técnica passada de "pai para filho", pode inspirar ou mesmo desvendar uma solução que se comprove cientificamente correta e produtivamente viável no aspecto econômico.

Então, de um momento para o outro, determinadas comunidades e seus conhecimentos transmitidos de geração em geração passaram a despertar a atenção de pesquisadores - muitos deles representando interesses comerciais de empreendimentos multinacionais. Com isso, informações até então restritas a um pequeno grupo alcançaram a condição de precioso insumo para pesquisas, ensejando proteção legal ao mesmo tempo em que conquistam reconhecimento do seu valor no meio acadêmico:

Cientistas descobrem modelos cognitivos complexos, sob domínio intelectual de populações tradicionais, pobres, excluídas, na maioria das vezes sem nenhuma educação formal. A importância deste conhecimento, seja como ferramenta local para compreender o mundo, seja como atalho para se produzir conhecimento "científico" a partir de "dicas" populares, ou ainda como patrimônio cultural da humanidade, vem sendo progressivamente reconhecido pelo mundo acadêmico ${ }^{17}$.

Não se trata de apropriação ou sujeição de um ao outro conhecimento, posto que os dois se constroem em chaves e em campos distintos, o que se denomina "regimes de conhecimento" próprios, mas podem se aproximar e fundir-se pelo propósito do resultado

\footnotetext{
${ }^{17}$ MOURA, Flávia de Barros Prado Moura. Conhecimento tradicional e estratégias de sobrevivência de populações brasileiras. EDUFAL: Maceió, 2007, p. 09.
} 


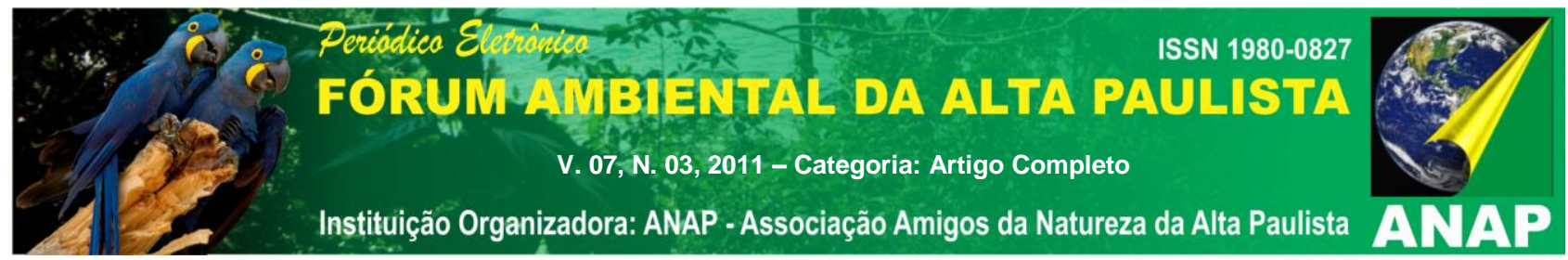

pretendido; enfim, são duas dimensões capazes de se encontrar. Paradoxalmente, nesse caso um uso artesanal de determinado material, substância, produto ou subproduto animal ou vegetal, portanto em mínima escala, constitui atalho para uma tecnologia de aproveitamento do mesmo recurso ou derivado em escala industrial; o manejo até então sustentado pode inspirar uma exploração sem compromisso com a preservação ambiental e, ainda, sem compensações pelo conhecimento tradicional associado colhido junto com as amostras de interesse comercial.

Em reação a tal movimento, contrapõem-se iniciativas para despertar a consciência dos próprios integrantes de comunidades locais, a fim de que conhecimentos não sejam utilizados gratuitamente, sem retorno aos titulares. Exemplo de ações nesse sentido, promovidas por órgãos públicos e privados, é a distribuição da cartilha ilustrada sobre conhecimentos tradicionais associados, no formato de quadrinhos, produzida em Belém, em 2005, pelo Núcleo de Propriedade Intelectual do Centro Universitário do Estado do Pará (CESUPA), em parceria com o SEBRAE - Serviço Brasileiro de Apoio às Micro e Pequenas Empresas ${ }^{18}$.

Junto com a consciência despertada, aflora uma espécie de expectativa de redenção coletiva justificada por uma vida simples, sem recursos financeiros, mas que preservou valores ambientais por ininterruptas gerações em comunidades tradicionais formadas por povos indígenas, por populações ribeirinhas e por quilombolas, entre outros. A percepção de valores culturais próprios ao lado de uma sensação de possível perda de uma única chance de compensação mobiliza lideranças comunitárias, fazendo com que a chegada de um pesquisador não mais seja vista apenas como a vinda de um possível bem-feitor, mas sim caracterizada pela desconfiança. E o contrato deve se estabelecer como garantia do equilíbrio de forças, em uma nova relação de poder.

Os dois lados interessados descobrem vantagens que devem ser compatibilizadas. Para os efeitos legais, ainda que apenas um indivíduo - membro da comunidade detenha um conhecimento tradicional associado ao patrimônio genético, como no caso de um pajé em uma tribo indígena, o grupo pode ser considerado titular desse conhecimento

\footnotetext{
${ }^{18}$ MOREIRA, Eliane e MILÉO, Bruno. Cartilha sobre conhecimentos tradicionais associados. Belém: CESUPA-SEBRAE, 2005.
} 


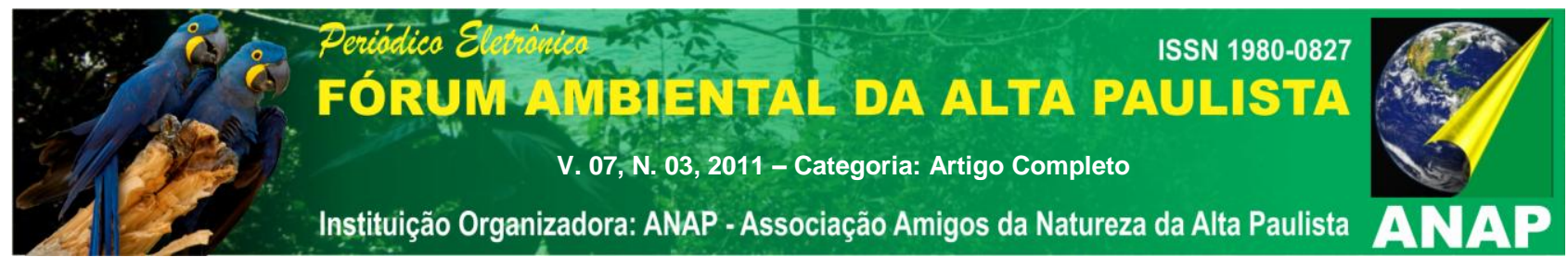

para o recebimento de benefícios ${ }^{19}$. Por outro lado, mais de um grupo pode ser reconhecido como titular desse mesmo saber, o que não raramente ocorre entre comunidades próximas, na situação de compartilhamento de conhecimentos.

Convém nesse momento analisar os dispositivos internacionais que tratam do tema. A CDB representou um marco em relação ao ideal aproveitamento e proteção da biodiversidade para todos os países dele signatários e, além de estabelecer os princípios da conservação e da sustentabilidade, previu a adoção de mecanismos que garantam os benefícios aos detentores desses recursos. Nesse propósito, são considerados os seus objetivos gerais, previstos no artigo 1ํㅜㅇㅡ.

A conservação da diversidade biológica, a utilização sustentável de seus componentes e a repartição justa e equitativa dos benefícios derivados da utilização dos recursos genéticos, mediante, inclusive, o acesso adequado aos recursos genéticos e a transferência adequada de tecnologias pertinentes, levando em conta todos os direitos sobre tais recursos e tecnologias, e mediante financiamento adequado ${ }^{20}$.

Em decorrência desse instrumento internacional e do aparato normativo dos diversos países signatários, surgiram exigências de negociações para obtenção de consentimento formal, além da previsão da repartição de benefícios com populações tradicionais para o acesso e a bioprospecção de interesse. Tanto os pesquisadores com propostas de produção estritamente acadêmica, quanto os pesquisadores voltados às intenções de empresas privadas em um mundo sem fronteiras para a obtenção de lucro, devem sujeitar-se às condições do escudo moldado para a proteção de uma expectativa de direitos associada à circulação de conhecimentos voltados ao manejo de produtos ou subprodutos do meio natural, de que são detentores comunidades tradicionais em países com expressiva diversidade biológica, como o Brasil.

O país foi um dos protagonistas da Convenção de Nagoya (10 ${ }^{a}$ Reunião da Conferência das Partes) em outubro de 2010, como relataram observadores, e obteve vitória ao defender, desde o início, que:

\footnotetext{
${ }^{19}$ Parágrafo único, do artigo 9º, da Medida Provisória n. 2.186-16 de 2001.

${ }^{20}$ BRASIL. A Convenção sobre Diversidade Biológica - CDB. Op. cit.
} 


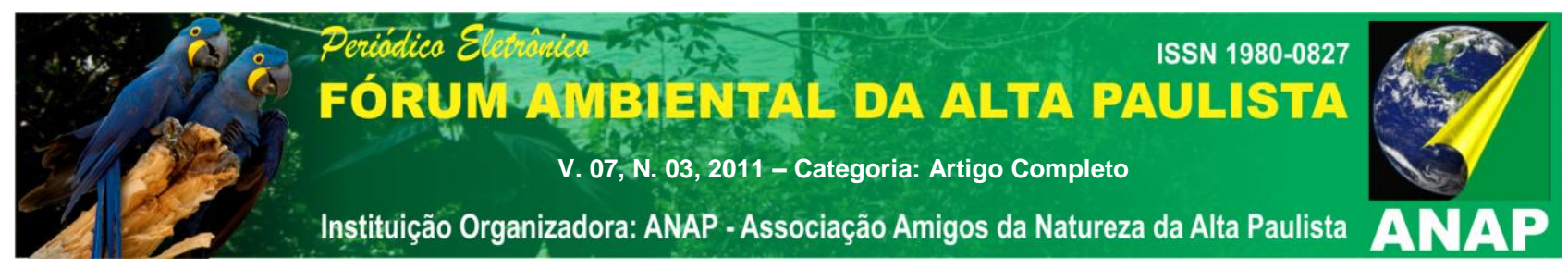

Não concordaria com um documento que não incluísse a repartição de benefícios e exigia que ela se estendesse aos derivados - a convenção trata dos recursos genéticos primários, mas é nos derivados que as indústrias farmacêuticas e de cosméticos buscam insumos para os seus produtos, como nos venenos de cobra, nos extratos, nos óleos ${ }^{21}$.

Como consequência das conversações, foi firmado um acordo (Protocolo de Nagoya) que determinou as regras básicas para o acesso e repartição de benefícios provenientes de utilização de componentes e derivados do patrimônio genético, resumido na sigla em inglês: ABS - Access and Benefit Sharing. Então, o que inicialmente a CDB apresentava como sugestão aos seus signatários, passou a constituir uma forma de obrigação política, nos termos do Protocolo que também se estabeleceu como uma referência para a formulação de cada legislação respectiva nos mesmos países, de modo harmonioso.

Criou-se em Nagoya, enfim, uma regra internacional que obriga os países a exigirem dos seus pesquisadores que comprovem a legalidade do acesso aos recursos genéticos que efetivaram em outros países, novidade que torna o quadro geral teoricamente mais igualitário, em tese beneficiando os países megadiversos (dentre os biodiversos, aqueles que possuem maior patrimônio genético) como o Brasil. Por outro lado, a novidade trouxe a expectativa de que a legislação brasileira seja em breve atualizada, acompanhando o ajustamento da legislação dos demais países:

Para garantir que seus direitos sejam respeitados, cada país também terá de se esforçar para estabelecer leis exequíveis... No âmbito de Nagoya, foi previsto um mecanismo de facilitação de informação onde cada nação que ratificar o compromisso deposite seu marco legal, que ficará disponível para quem se interessar ${ }^{22}$.

No caso brasileiro, o texto do Projeto de Lei em trâmite deverá ser revisto, a fim de se adaptar às novas regras internacionais.

Mas não apenas as questões discutidas entre representantes da comunidade internacional constituem motivo do debate contemporâneo. Tratando-se o conhecimento

\footnotetext{
${ }^{21}$ GIRARDI, Giovana. Biodiversidade além do alcance. Revista Unespciência, dezembro de 2010, ed. 15, p. 22.

22 Ibid, p. 23.
} 


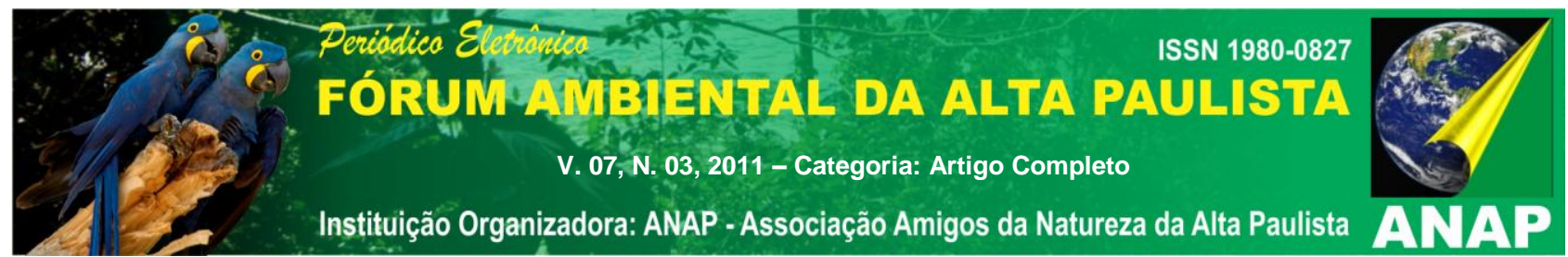

tradicional de item cultural que integra a identidade de um ou mais grupos, no âmbito interno mantêm-se disputas na pretensão de se definir a titularidade desse bem imaterial. Como exemplo, um conhecimento tradicional nas aldeias indígenas e sua trajetória em face de direitos intelectuais a ele vinculados foram relatados pela antropóloga Manuela Carneiro da Cunha: trata-se do caso emblemático da utilização do "kampô", tipo de secreção de uma espécie de rã ${ }^{23}$.

A autora descreve com riqueza de detalhes que a discussão teve início com o recebimento de uma carta que os Katukina (do Acre) encaminharam a então Ministra do Meio Ambiente Marina Silva, em abril de 2003, com reivindicação de direitos em razão do uso tradicional da substância para fins terapêuticos e melhora de desempenho físico. Em razão de que vários grupos étnicos, inclusive do Peru (que possui legislação diversa referente a proteção de direitos sobre bens imateriais), utilizavam-se do mesmo recurso, como seria possível realizar a repartição de benefícios do conhecimento tradicional associado? Nota-se que, desde a década de 1990, muitas patentes foram registradas em países diversos, envolvendo a mesma substância e seus derivados.

Apesar da boa vontade demonstrada no presente caso, a discussão sobre a forma correta e justa de partilhar os benefícios na condição relatada - em que o conhecimento tradicional e seus resultados despertaram a atenção de estudiosos e provocaram pesquisas -, continua sem solução por conta da pluralidade dos agentes interessados e a falta de consenso, circunstância que acaba também por prejudicar o desenvolvimento científico.

\section{CONCLUSÃO}

O tema da biodiversidade mantém relação estreita com o reconhecimento dos direitos de propriedade intelectual e repartição de benefícios, a partir de um patrimônio genético característico de determinada área geográfica, não raras vezes associado a

${ }^{23}$ CUNHA, Manuela Carneiro da. "Cultura" e cultura: conhecimentos tradicionais e direitos intelectuais (capítulo 19). In: Cultura com aspas e outros ensaios. São Paulo: Cosac Naify, 2009, p. p. 311 a 373. 


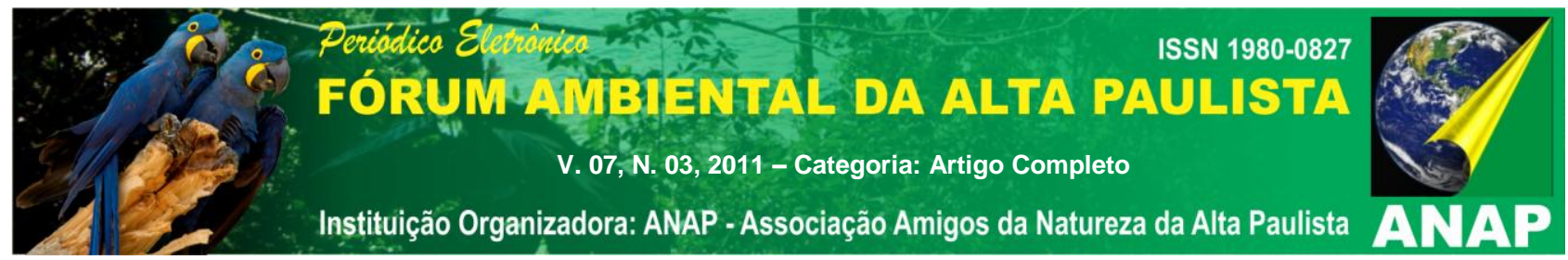

conhecimentos tradicionais de comunidades locais. Esses conhecimentos inseparáveis dos recursos do meio natural integram a própria identidade cultural de povos tradicionais e conquistam igual consideração no ordenamento jurídico de expressão internacional.

A postura de reconhecer institucionalmente esses direitos e de propiciar condições para a manutenção dessas comunidades e suas relações produtivas com a natureza também integra os esforços de preservação da biodiversidade. Já se demonstrou que são as práticas e inovações, em tal campo, que em muitos casos conservam a biodiversidade biológica dos ecossistemas do país, particularmente das florestas tropicais e, ainda, os agricultores tradicionais são igualmente responsáveis pela conservação da agrobiodiversidade ao colocarem em prática diversos saberes sobre plantas domesticadas e cultivadas, além do manejo de ecossistemas cultivados. Constitui, portanto, um avanço no sistema legal o surgimento de novos direitos vinculados à proteção jurídica da diversidade biológica e cultural ${ }^{24}$.

Como normalmente acontece com os "novos direitos", testemunha-se o aparecimento de tensões com base no mecanismo normativo de pesos e contrapesos que impõe deveres para a garantia dos preconizados direitos, em face da tutela do Estado, quando se tratam de interesses legítimos e estratégicos para o desenvolvimento nacional. Momento, portanto, de ajustar a legislação para que se possa atingir um equilíbrio capaz de garantir aqueles benefícios e ao, mesmo tempo, se alcance sucesso no incentivo a pesquisa e o desenvolvimento científico, no ambiente em que se assentam os trilhos do aproveitamento justo do patrimônio genético característico do Brasil.

Em razão das dificuldades de composição dos interesses envolvidos, a legislação continuará provavelmente impondo contratos previamente registrados para a divisão de benefícios. Alguns casos de sucesso apresentam fórmula equitativa de possível distribuição - em sede de uma expectativa de direitos -, em partes iguais entre instituição financiadora, universidade, pesquisador responsável e comunidade. Talvez seja essa a melhor solução.

Diante de um ideal de atualização normativa daquilo que se revela marca do tempo presente a experiência do "provisório" aparato legislativo serviu para a quebra de

\footnotetext{
${ }^{24}$ SANTILLI, Juliana. Socioambientalismo e novos direitos: proteção jurídica à diversidade biológica e cultural. São Paulo: Peirópolis. 2005, p. 195.
} 


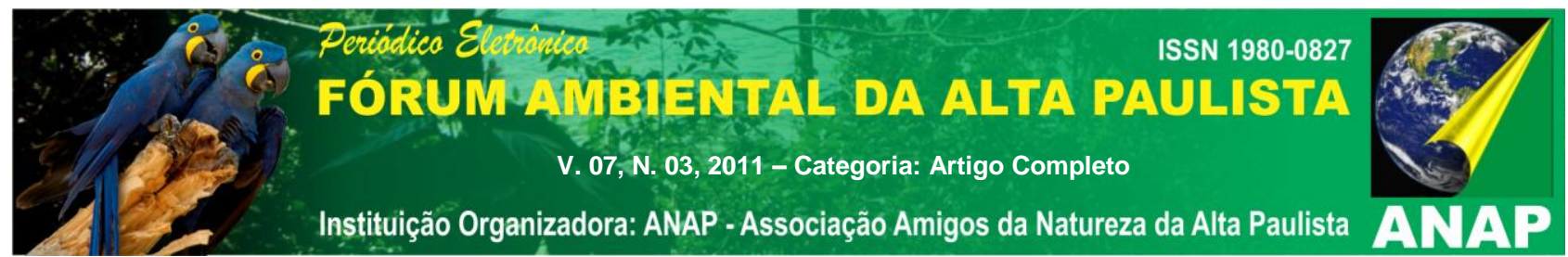

paradigmas e, assim, não houve tempo perdido. Superou-se, por exemplo, a ideia de um coletivismo absoluto nas sociedades indígenas. Por outro lado, compreende-se uma dicotomia que pode ser definida pela coexistência das expressões de cultura com e sem aspas, ou seja, entre propriedade intelectual coletiva ("cultura”) e o domínio público (cultura), como definiu Manuela Carneiro da Cunha ${ }^{25}$. Surgem, então, novas formas de representação com "existência jurídica" - no gênero associação -, impondo-se um preliminar debate sobre a legitimidade dessa representação; pois quando existem mais de uma associação, quem se considerará legítimo representante dos interesses do grupo?

Para evitar decisões não satisfatórias a qualquer das partes pela suspensão da pesquisa, algumas entidades defendem a previsão de mecanismos de resolução de controvérsias sempre presentes, por conta da diversidade de povos indígenas no país (hoje totalizando 241 povos), além da existência de outros povos tradicionais remanescentes, e a espécie de conhecimento identificado nesse novel campo jurídico como "compartilhado". Até então, poder-se-ia cogitar apenas as figuras da propriedade intelectual privada, da coletiva (de um grupo limitado) e da difusa - ou de domínio público (sem titulares definidos). Ainda, cogita-se a criação de um fundo para destino obrigatório de parte dos recursos provenientes das utilizações do patrimônio genético e dos conhecimentos associados com o intuito de democratizar o seu acesso, juntamente com a promoção da própria biodiversidade.

Naturalmente, as soluções de conflitos deverão contemplar a organização social desses povos, de modo a viabilizar uma arbitragem. Os novos e inesperados questionamentos exigem, no mesmo patamar, inéditas posturas e decisões: a dinâmica das circunstâncias também é marca da cultura, ela própria em constante movimento, como um pulsante sinal de vida, representação maior da biodiversidade.

\section{REFERÊNCIAS}

BRASIL. A Convenção sobre Diversidade Biológica - CDB. Brasília: Ministério do Meio Ambiente, Secretaria de Biodiversidade e Florestas, 2000.

${ }^{25}$ CUNHA. Op. cit, 


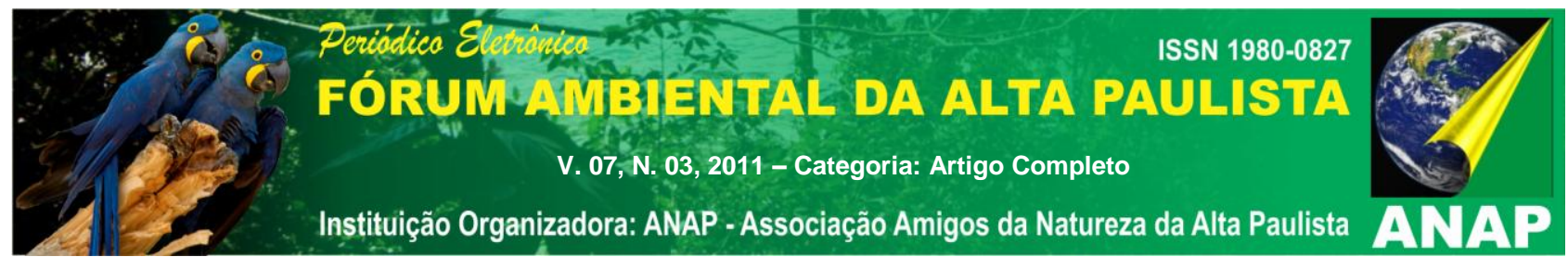

BRESSAN, Paulo Magalhães, KIERULFF, Maria Cecília Martins, SUGIEDA, Angélica Midori: coordenação geral. Fauna ameaçada de extinção no estado de São Paulo. São Paulo: Fundação Parque Zoológico de São Paulo, 2009.

CUNHA, Manuela Carneiro da. Cultura com aspas e outros ensaios. São Paulo: Cosac Naify, 2009.

GIRARDI, Giovana. Biodiversidade, essa desconhecida. Jornal "O Estado de São Paulo". 07 de agosto de 2008. ed. 15, p. 20 a 27.

Biodiversidade além do alcance. Revista Unespciência, dezembro de 2010,

KINGSLEY, Rebecca. Espécies ameaçadas: guia prático. Por Rebecca Kingsley. São Paulo: Nobel, 1999.

LEONE, Cínthia. Cientistas criticam lei de bioprospecção. Jornal da UNESP, ano XXII, n. 262, dezembro de 2010.

MOREIRA, Eliane e MILÉO, Bruno. Cartilha sobre conhecimentos tradicionais associados. Belém: CESUPA-SEBRAE, 2005.

MOREIRA, Teresa Cristina. Conhecimentos tradicionais associados à biodiversidade no Brasil e a sua abordagem jurídica no limiar do século biotecnológico. In GROSTEIN, Marta Dora, org. Ciência ambiental: questões e abordagens. São Paulo: Annablume; FAPESP, 2008.

MOURA, Flávia de Barros Prado Moura. Conhecimento tradicional e estratégias de sobrevivência de populações brasileiras. EDUFAL: Maceió. 2007.

NAIME, Roberto. Sistemas, Riqueza e a Biodiversidade. Artigo publicado no portal "Ecodebate" em 29-11-2010. Disponível em: <http://www.ecodebate.com.br/2010/11/29/ sistemas-riqueza-e-a-biodiversidade-artigo-de-roberto-naime/>. Acesso em: 31 dez. 2010.

NASSIF, Luis. O cerco à biopirataria. Artigo publicado em 06.05.2011, disponível em: $<$ http://www.advivo.com.br/blog/luisnassif/o-cerco-a-biopirataria>. Acesso em: 25 mai. 2011.

SAE. Estímulo à pesquisa em biodiversidade. Brasília: Portal SAE. Disponível em: <http://www.sae.gov.br/site/?p=459>. Acesso em: 02 jan. 2011.

SANTILLI, Juliana. Socioambientalismo e novos direitos: proteção jurídica à diversidade biológica e cultural. São Paulo: Peirópolis. 2005.

SECRETARIADO DA CONVENÇÃO SOBRE DIVERSIDADE BIOLÓGICA. Panorama da Biodiversidade Global 3. Brasília: Ministério do Meio Ambiente, Secretaria de Biodiversidade e Florestas, 2010. 


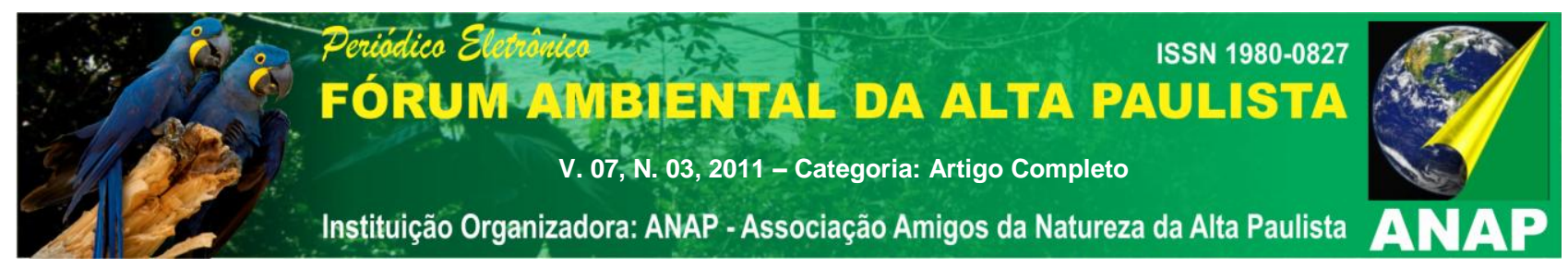

SYLVIA, Miguel. Conferência da ONU sobre Diversidade Biológica (COP-10): As conquistas de Nagoya. Artigo publicado em 25 nov. 2010, Revista Ecologia, fonte: jornal da USP. Disponível em: <http://revistaecologica.com/index.php?option=com_content\&view $=$ article $\&$ id=470: conferencia-da-onu-sobre-diversidade-biologica-cop-10-as-conquistas-denagoya\&catid=121 :cop10 $>$. Acesso em: 02 jan. 2011.

UNESCO. 2010 - Ano Internacional da Biodiversidade. Disponível em: $<$ http://www.unesco.org/pt/brasilia/about-the-unesco-brasilia-office/prizes-and-celebrations -in-brazil/2010-international-year-of-biodiversity/>. Acesso em: 31 dez. 2010. 